Journal of Medical and Biomedical Sciences (2017) 6(1): 35-43

C) UDS Publishers Limited All Right Reserved 2026-6294

ORIGINAL ARTICLE

doi: http://dx.doi.org/10.4314/jmbs.v6i1.5

\title{
A Comparative Study of Cox Regression vs. Log-Logistic Regression (with and without its frailty) in Estimating Survival Time of Patients with Colorectal Cancer
}

\author{
A.H. Hashemian ${ }^{1,2}$, M. Garshasbi ${ }^{3}$, M.A. Pourhoseingholi4, and S. Eskandari ${ }^{5}$ \\ ${ }^{1}$ Research Center for Environmental Factors Affecting Health, 2,3 Department of Biostatistics, Faculty of Public Health, ${ }^{5}$ Member of \\ Student Research Committee, Kermanshah University of Medical Sciences, Kermanshah, ${ }^{4}$ Gastroenterology and Liver Diseases Research \\ Center, Research Institute for Gastroenterology and Liver Diseases, Shabid-Beheshti University of Medical Sciences, Tehran, Iran.
}

\begin{abstract}
Colorectal cancer is common and lethal disease with different incidence rate in different parts of the world which is taken into account as the third cause of cancer-related deaths. In the present study, using non-parametric Cox model and parametric Log-logistic model, factors influencing survival of patients with colorectal cancer were evaluated and the models efficiency were compared to provide the best model. This study is conducted on medical records of 1127 patients with colorectal cancer referred to Taleghani Medical and Training Center of Tehran between 2001 2007 and were definitely diagnosed with cancer, pathologically. Semi-parametric Cox model and parametric log-logistic model were fitted. Akaike's criterion of Cox Snell graph was used to compare the models. To take into account non-measured individual characteristics, frailty was added to Cox and log-logistic models. All calculations were carried out using STATA software version 12 and SPSS version 20.0, at the 0.05 level of significance. From a total of 1127 patients studied in this research, there were 690 men and 437 women. According to non-parametric Kaplan-Meier method, chances of surviving for 1, 3, 5 and 7 years were 91.16, 73.20, 61.00, and 54.94, respectively. Addition of frailty parameter did not change the model outcome. The results of fitting classified Cox and log-logistic models showed that body mass index (BMI), tumor grade, tumor size, and spread to lymph nodes, were the factors affecting survival time. Based on comparisons, and according to Cox Snell residuals, Cox and log-logistic models had almost identical results; however, because of the benefits of parametric models, in surveying survival time of patients with colorectal cancer, log-logistic can be replaced, as a parametric model, with Cox model.
\end{abstract}

Journal of Medical and Biomedical Sciences (2017) 6(1), 35-43

Keywords: Colorectal cancer, Cox regression, Log-logistic model, Cox Snell residual

\section{INTRODUCTION}

Colorectal cancer (CRC) is one of the most important cancers throughout the world and is the most type of common gastrointestinal cancers. Its incidence and mortality rates are different around the world. The highest incidence of CRC has been reported in North America and Europe while the low-

Correspondence: Mozhgan Garshasbi, Department of Biostatistics and Epidemiology, Faculty of Public Health, Kermanshah University of Medical Sciences.

Email:m.garshasbi67@gmail.com est incidences have been reported in Asia, Africa and South America (Stewart and Kleihues, 2003; Melissa et al., 2009). Generally it kills about one third of patient affected with this type of malignancy (Parkin, 2001).

Colorectal cancer is a common and lethal disease that is related to environmental as well as genetic factors. Different genetic, epidemiologic, and experimental studies have shown that CRC appears as a result of interaction of genetic predisposition, environmental factors and life style. Annual inci- 


\section{Cox vs log-logistic modeling in CRC patients}

Hashemian et al.,

dence rate of CRC in Iran is about 6-7.9 per 100,000 and is the fourth common type of cancer (Sadjadi et al., 2003). With mortality rate about 1.198 per 100,000 , it accounts for nearly $13 \%$ of deaths caused by gastrointestinal cancers and $5.3 \%$ of nonaccidental deaths in Iran (Ganji et al., 2006). Given the relatively high prevalence of this cancer in Iran, and among young people, it has imposed a huge social and economic burden on society and patients. Early diagnosis of colorectal neoplasms, as soon as possible, is very effective in promoting patients' health and increasing their survival time before they become symptomatic (Angell-Andersen et al., 2004).

Survival models are statistical techniques to estimate the survival time and find the related factors or predict the outcome (Ahmad Reza Baghestani et al., 2015). There are two major regression models used for right censored data: proportional hazards model (Cox) as a semi parametric method and accelerated failure time model as a parametric model. Many of the standard parametric models such as Weibull, Exponential and Log logistic are accelerated failure time models (Pourhoseingholi MA et al., 2007).

Cox semi-parametric model is the most common regression model used in the analysis of survival data (Cox, 1972). However, parametric models may be preferred to Cox model (Kalbfleisch and Prentice, 1980; Lawless, 1998) and under certain conditions, provide more effective estimation than Cox models (Efron, 1977; Oakes, 1977). In order to use Cox model, Proportional Hazards (PH) assumption should be met for all independent variables in the final model, i.e. risk ratio should be constant over time. In case the assumption is met, interpretation of the obtained model would be simple than parametric models. Otherwise, classified Cox model can be used and risk ratio need not to be calculated for variables that the hypothesis does not hold. What is more, consideration of hypothesis and selection of a probability distribution for survival time, makes statistical inference more accurate and results in smaller estimated standard deviation compared with when such assumptions do not exist (Klein and Moeschberger).

In survival analysis, when mortality reaches maxi- mum and then gradually decreases, after a finite period, a model with heterogeneous fragility should be added. Log-logistic and lognormal models have this property and are also similar in terms of form. But since there is no closed form for survival and risk functions in log-normal model, for simple computing, it is better to use Log-logistic model (Kleinbaum and Klein, 2005). Yet, Log-logistic distribution is a good approximation for log-normal distribution and is preferred over lognormal distribution because it has simple expressions for hazard and survival functions and also Log-logistic distribution is easier to use when dealing with data that include censored observations.

Meanwhile, unless you have outlier data, it gives good approximation for log-normal distribution. Also Log-logistic is the only parametric models with two properties of proportional odds ratio and accelerated failure time (Lawless, 1998; Kleinbaum and Klein, 2005). Survival analysis models are usually studied based on the assumption of homogeneity of the study population, while due to individual unobservable random effects; such assumption is not often realistic. Therefore, in this case, mixed models with random effects are recommended that are known as frailty model in survival analysis (Saki Malehi et al.). The aim of this study was to compare the performance of semi-parametric Cox model and parametric log-logistic model to estimate survival time of patients with CRC and choose the best model.

\section{MATERIALS AND METHODS}

\section{Study site}

This study is conducted on medical records of 1127 patients with CRC who referred to Taleghani medical and training hospital, Tehran, Iran, between 2001 and 2007 and was definitely diagnosed with cancer, pathologically. This research is conducted with the permission of Department of Research and approval of Ethics Committee of Kermanshah University of Medical Sciences (95046).

\section{Data collection}

Age at the time of diagnosis, gender, family history, smoking, body mass index (BMI), location of the 


\section{Cox vs log-logistic modeling in CRC patients Hashemian et al.,}

tumor, tumor grade, pathologic stage, metastasis to other organs, pathology primary tumor, morphology of cancer, spread to surrounding lymph nodes and tumor size were included in this study.

Semi-parametric Cox model and parametric loglogistic model were fitted and then frailty was added to models. The frailty $\alpha$ is an unobserved multiplicative effect on the hazard function assumed to follow some distribution $g(\alpha)$ with $\alpha>0$ and the mean of $\alpha$ equal to 1 . The variance of $\alpha$ is a parameter $\theta$ (theta) that is typically estimated from the data. An individual's hazard function conditional on the frailty can be expressed as a multiplied by $\mathrm{h}(\mathrm{t})$.

$h(t \mid \alpha)=\alpha h(t)$

Any distribution for $\alpha>0$ with a mean of 1 can theoretically be used for the distribution of the frailty. Two distributions; the gamma distribution and the Inverse-Gaussian distribution are most widely employed distributions for the frailty. With the mean fixed at 1 , both these distributions are parameterized in terms of the variance $\theta$ and typically yield similar results. In this study, gamma distribution was used for the frailty.

\section{Statistical analysis}

Akaike's criterion was used to compare the models efficiency but since methods to obtain parameters are different for Cox and log-logistic models, Cox Snell residual graph was employed for evaluating fitted models. Survival data analysis carried out using STATA software version 12 and SPSS version 16, at the 0.05 level of significance.

\section{RESULTS}

From total of 1127 patients studied in this research, $690(61.2 \%)$ were men and $437(38.8 \%)$ women. The mean of survival for patients was $105(95 \%$ CI:95-115) months and the Median was 94.5 (95\% CI:58.6-130.4) months. According to non-parametric Kaplan-Meier method, chances of surviving for 1, 3, 5 , and years were $91.2,73.20,61.00$, and 54.94, respectively. About 236 (20.9\%) out of 1127 patients with CRC died of which $63.5 \%$ were men. The results of multivariate Cox and log-logistic models were indicated significant difference between BMI, tumor grade, tumor size and spread to lymph nodes (Table 1).

According to the results from multivariate loglogistic models, patients with poorly differentiated and moderately differentiated tumor grade respectively have 2.32 (95\% CI; 1.48-3.63) and 1.39 (95\% CI;1.06-1.82) times more hazard than those patients in the reference category of well differentiated tumors. Patients with BMI of all categories (18.6 -24.9, 25-29.9 and >30) had hazard less than those patients in the reference category. Also stronger hazard of death was observed for spread to lymph nodes N1 (HR $=2.16,95 \% \mathrm{CI} ; 1.25-3.74) \mathrm{com}-$ pared to reference category of spread to lymph nodes $\mathrm{N} 0$, and Hazard of patients with tumor size more than $35 \mathrm{~mm}$ was 1.88 (95\% CI;1.40-2.51) times higher than those patients in reference category (Table 2).

The factor of frailty parameter in the survival of patient with colorectal cancer using Cox model result and Log-logistic model results are shown in Table 3. Poor tumor grade $(\mathrm{OR}=1.90 ; 95 \%$ $\mathrm{CI}=1.24-2.91 ; \mathrm{p}=0.003)(\mathrm{OR}=2.32 ; 95 \% \mathrm{CI}=1.48$ 23.63; $\mathrm{p}=0.002)$, tumor size $>35(\mathrm{OR}=1.73 ; 95 \%$ $\mathrm{CI}=1.27-2.36 ; \mathrm{p}=0.001)(\mathrm{OR}=1.88 ; 95 \% \mathrm{CI}=1.40$ 2.51; $\mathrm{p}=0.001$ ) and BMI (normal weight; $\mathrm{p}<0001$, overweight; $\mathrm{p}<0001$ and obese; $\mathrm{p}<0001$ ) in both Cox model and Log-logistic model were the variables that significantly increased in frailty parameters.

In order to evaluate the appropriateness and compare the fitted models, Cox Snell residual graph was plotted for Cox and log-logistic models (Figure 1). The best model is the one that its residual graph is closer to bisector line. As the graph shows, both models are fitted properly.

\section{Discussion}

In this study, BMI, tumor grade, tumor size and spread to lymph nodes were prognostic factors of CRC survival, based on comparisons, and according to Cox Snell residuals, Cox and log-logistic models had almost identical results; however, be- 


\section{Cox vs log-logistic modeling in CRC patients}

Hashemian et al.,

Table 1: Cox model results; univariate and multivariate analysis of survival of patients with colorectal cancer

\begin{tabular}{|c|c|c|c|c|}
\hline \multirow[t]{2}{*}{ Variable } & \multicolumn{2}{|c|}{ Univariate } & \multicolumn{2}{|c|}{ Multivariate* } \\
\hline & OR $(95 \% \mathrm{CI})$ & P-Value & $\operatorname{aOR}(95 \% \mathrm{CI})$ & P-Value \\
\hline \multicolumn{5}{|c|}{ Age at the time of diagnosis } \\
\hline $\begin{array}{l}45-65 \\
>65\end{array}$ & $\begin{array}{l}0.95(0.70-1.28) \\
1.23(0.88-1.73)\end{array}$ & $\begin{array}{l}0.73 \\
0.22\end{array}$ & $\begin{array}{l}1.03(0.76-1.41) \\
1.23(0.87-1.73)\end{array}$ & $\begin{array}{l}0.84 \\
0.24\end{array}$ \\
\hline \multicolumn{5}{|l|}{ BMI } \\
\hline $\begin{array}{l}18.6-24.9 \\
25-29.9 \\
>30\end{array}$ & $\begin{array}{l}0.55) 0.39-0.78) \\
0.28(0.19-0.42) \\
0.23(0.11-0.46)\end{array}$ & $\begin{array}{c}0.001 \\
<0.001 \\
<0.001\end{array}$ & $\begin{array}{c}0.47(0.33-0.66) \\
0.24(0.16-0.37) \\
0.20(0.01-0.4)\end{array}$ & $\begin{array}{l}<0.001 \\
<0.001 \\
<0.001\end{array}$ \\
\hline \multicolumn{5}{|l|}{ Family history } \\
\hline $\begin{array}{l}\text { yes } \\
\text { Tumor grade } \\
\text { well }\end{array}$ & $0.85(0.65-1.11)$ & 0.23 & $0.93(0.70-1.22)$ & 0.582 \\
\hline $\begin{array}{l}\text { moderately } \\
\text { poorly }\end{array}$ & $\begin{array}{l}1.26(0.96-1.66) \\
1.74(1.16-2.61)\end{array}$ & $\begin{array}{l}0.099 \\
0.007\end{array}$ & $\begin{array}{l}1.35(1.02-1.78) \\
1.90(1.24-2.91)\end{array}$ & $\begin{array}{l}0.035 \\
0.003\end{array}$ \\
\hline $\begin{array}{l}\text { Tumor size } \\
<35 \mathrm{~mm}\end{array}$ & & & & \\
\hline $\begin{array}{l}>35 \mathrm{~mm} \\
\text { Pathology prir } \\
\text { T0 }\end{array}$ & 1.46(1.09-1.95) & 0.011 & $1.73(1.27-2.36)$ & 0.001 \\
\hline $\begin{array}{l}\text { T1 } \\
\text { Spread to lym } \\
\text { N0 }\end{array}$ & $1.56(1.18-2.06)$ & 0.002 & $1.34(0.92-1.94)$ & 0.131 \\
\hline $\begin{array}{l}\text { N1 } \\
\text { Metastasis }\end{array}$ & $1.62(1.25-2.10)$ & $<0.001$ & $1.92(1.10-3.33)$ & 0.021 \\
\hline $\begin{array}{l}\text { M1 } \\
\text { Pathologic sta } \\
\text { early stag }\end{array}$ & $1.69(1.26-2.25)$ & $<0.001$ & $1.21(0.78-1.86)$ & 0.393 \\
\hline advanced stage & $1.50(1.15-1.95)$ & 0.003 & $0.70(0.39-1.28)$ & $\begin{array}{c}0.252 \\
\mathrm{AIC}=2347.282^{*}\end{array}$ \\
\hline
\end{tabular}

\section{OR; odd ratio or hazard ratio; aOR; adjusted odd ratio; $p<0.05$ was statistically significant}

cause of the benefits of parametric models, in surveying survival time of patients with colorectal cancer, log-logistic can be replaced, as a parametric model, with Cox model.

In many studies, metastasis to nearby lymph nodes is introduced as an independent variable associated with survival of patients (Berti et al., 1983; Park et al., 1999; OGATA et al., 2005). Also, in the current study, the variable relationship with survival time was significant in both univariate and multivariate analysis. In evaluation of pathologic factors by uni- variate method, stage of disease had a direct correlation with patient survival while by multivariate method no significant correlation with prognosis of patients was observed. Sue et al. also found significant correlation between stage of disease and patients survival (Xu et al., 2006). Li Yang et al. reported significant correlation between patients' survival and colon cancer using univariate method; however multivariate method did not show the same result (Liang et al., 2006). 
Cox vs log-logistic modeling in CRC patients

Hashemian et al.,

Table 2: Log-logistic model results; univariate and multivariate analysis of survival of patients with colorectal cancer

\begin{tabular}{|c|c|c|c|c|}
\hline \multirow{2}{*}{ Variables } & \multicolumn{2}{|c|}{ Univariate } & \multicolumn{2}{|c|}{ Multivariate* } \\
\hline & OR $(95 \% \mathrm{CI})$ & P-Value & OR $(95 \% \mathrm{CI})$ & P-Value \\
\hline \multicolumn{5}{|c|}{$\begin{array}{l}\text { Age at the time of diagnosis } \\
<45\end{array}$} \\
\hline $45-65$ & $0.98(0.71-1.35)$ & 0.920 & $1.06(0.78-1.45)$ & 0.774 \\
\hline$>65$ & $1.29(0.89-1.84)$ & 0.204 & $1.28(0.90-1.82)$ & 0.253 \\
\hline \multicolumn{5}{|l|}{ BMI } \\
\hline \multicolumn{5}{|l|}{$<18.5$} \\
\hline $18.6-24.9$ & $0.46(0.31-0.68)$ & 0.001 & $0.38(0.26-0.57)$ & $<0.001$ \\
\hline $25-29.9$ & $0.22(0.14-0.35)$ & $<0.001$ & $0.18(0.12-0.29)$ & $<0.001$ \\
\hline$>30$ & $0.18(0.09-0.36)$ & $<0.001$ & $0.15(0.07-0.30)$ & $<0.001$ \\
\hline \multicolumn{5}{|l|}{ Family history } \\
\hline \multicolumn{5}{|l|}{ no } \\
\hline yes & $0.82(0.62-1.08)$ & 0.2 & $0.88(0.67-1.15)$ & 0.420 \\
\hline \multicolumn{5}{|l|}{$\begin{array}{l}\text { Tumor grade } \\
\text { well }\end{array}$} \\
\hline moderately & $1.32(0.99-1.77)$ & 0.087 & $1.39(1.06-1.82)$ & 0.050 \\
\hline poorly & $2.05(1.31-3.22)$ & 0.004 & $2.32(1.48-3.63)$ & 0.002 \\
\hline \multicolumn{5}{|l|}{ Tumor size } \\
\hline$<35 \mathrm{~mm}$ & & & & \\
\hline$>35 \mathrm{~mm}$ & $1.52(1.13-2.05)$ & 0.014 & $1.88(1.40-2.51)$ & 0.001 \\
\hline \multicolumn{5}{|c|}{ Pathology primary tumor } \\
\hline T1 & $1.63(1.21-2.20)$ & 0.004 & $1.28(0.87-1.86)$ & 0.263 \\
\hline \multicolumn{5}{|c|}{ Spread to lymph nodes } \\
\hline \multicolumn{5}{|l|}{ No } \\
\hline N1 & $1.79(1.36-2.34)$ & $<0.001$ & $2.16(1.25-3.74)$ & 0.021 \\
\hline \multicolumn{5}{|l|}{ Metastasis } \\
\hline \multicolumn{5}{|l|}{ M0 } \\
\hline M1 & $1.81(1.31-2.48)$ & 0.001 & $1.35(0.86-2.12)$ & 0.262 \\
\hline \multicolumn{5}{|c|}{$\begin{array}{l}\text { Pathologic stage } \\
\text { early stage }\end{array}$} \\
\hline advanced stage & $1.62(1.23-2.12)$ & 0.002 & $0.67(0.36-1.23)$ & $\begin{array}{c}0.280 \\
\mathrm{AIC}=1463.67^{*}\end{array}$ \\
\hline
\end{tabular}

\section{OR; odd ratio or hazard ratio; aOR; adjusted odd ratio; $p<0.05$ was statistically significant}

Although tumor stage at diagnosis is related to prognosis, since this factor is a function of tumor metastasis, it shows no significant correlation with patients' survival in multivariate method. Many studies have shown that metastasis, as an independent variable, is associated with patients' survival (Liang et al., 2006; Xu et al., 2006). These findings are consistent with results of analysis by univariate method. In both univariate and multivariate analysis, tumor size was a significant factor. Yet, in a study conducted by Lee et al., the effect of tumor size was not a significant diagnostic factor for colon and rectum cancers
(Li et al., 2008). Tumor grade was significant diagnostic factor in multivariate analysis.

Survival of patients with well differentiated tumors was more than those whose tumors were poorly differentiated which is consistent with the results of similar studies (Chung et al., 1982; Phillips et al., 1984; Goh et al., 1987; Cusack et al., 1996; Takahashi et al., 2000).

Although in the present study, family history of cancer was not significant, despite the findings of 


\section{Cox vs log-logistic modeling in CRC patients}

Hashemian et al.,

Table 3: Cox model results vs Log-Logistic model results with factor of frailty in the survival of patients with colorectal cancer

\begin{tabular}{|c|c|c|c|c|}
\hline \multirow[t]{2}{*}{ Variable } & \multicolumn{2}{|c|}{ Cox model } & \multicolumn{2}{|c|}{ Log-logistic model } \\
\hline & OR $(95 \%$ CI $)$ & P-Value & OR $(95 \%$ CI $)$ & P-Value \\
\hline \multicolumn{5}{|c|}{$\begin{array}{l}\text { Age at the time of diagnosis } \\
<45\end{array}$} \\
\hline $45-65$ & $1.03(0.76-1.41)$ & 0.84 & $1.06(0.78-1.45)$ & 0.774 \\
\hline$>65$ & $1.23(0.87-1.73)$ & 0.24 & $1.28(0.90-1.82)$ & 0.252 \\
\hline \multicolumn{5}{|l|}{ BMI } \\
\hline \multicolumn{5}{|l|}{$<18.5$} \\
\hline $18.6-24.9$ & $0.47(0.33-0.66)$ & $<0.001$ & $0.38(0.26-0.57)$ & $<0.001$ \\
\hline $25-29.9$ & $0.24(0.16-0.37)$ & $<0.001$ & $0.18(0.12-0.29)$ & $<0.001$ \\
\hline$>30$ & $0.20(0.01-0.4)$ & $<0.001$ & $0.15(0.07-0.3)$ & $<0.001$ \\
\hline \multicolumn{5}{|l|}{$\begin{array}{l}\text { Family history } \\
\text { no }\end{array}$} \\
\hline yes & $0.93(0.70-1.22)$ & 0.58 & $0.88(0.67-1.15)$ & 0.42 \\
\hline \multicolumn{5}{|l|}{$\begin{array}{l}\text { Tumor grade } \\
\text { well }\end{array}$} \\
\hline moderately & $1.35(1.02-1.78)$ & 0.034 & $1.39(1.06-1.82)$ & 0.05 \\
\hline poorly & $1.90(1.24-2.91)$ & 0.003 & $2.32(1.48-3.63)$ & 0.002 \\
\hline \multicolumn{5}{|l|}{ Tumor size } \\
\hline \multicolumn{5}{|l|}{$<35 \mathrm{~mm}$} \\
\hline$>35 \mathrm{~mm}$ & $1.73(1.27-2.36)$ & 0.001 & $1.88(1.40-2.51)$ & 0.001 \\
\hline \multicolumn{5}{|c|}{$\begin{array}{l}\text { Pathology primary tumor } \\
\text { T0 }\end{array}$} \\
\hline T1 & $1.34(0.92-1.94)$ & 0.13 & $1.28(0.87-1.86)$ & 0.263 \\
\hline \multicolumn{5}{|c|}{$\begin{array}{l}\text { Spread to lymph nodes } \\
\text { N0 }\end{array}$} \\
\hline N1 & $1.92(1.10-3.33)$ & 0.021 & $2.16(1.25-3.74)$ & 0.021 \\
\hline \multicolumn{5}{|l|}{ Metastasis } \\
\hline M1 & $1.21(0.78-1.86)$ & 0.39 & $1.35(0.86-2.12)$ & 0.262 \\
\hline \multicolumn{5}{|l|}{$\begin{array}{l}\text { Pathologic stage } \\
\text { early stage }\end{array}$} \\
\hline \multicolumn{4}{|l|}{ Shape } & 0.28 \\
\hline Variance of Frailty & 0.9 & $\begin{array}{c}0 \\
\mathrm{AIC}=2347.192\end{array}$ & 0.85 & AIC $=1465.67$ \\
\hline
\end{tabular}

OR; odd ratio or hazard ratio; $p<0.05$ was statistically significant

this study, some studies have shown that family history of cancer is known as a factor influencing the survival of patients with CRC (Ghadimi et al:; Ahmadi et al., 2014).

In this study, BMI was significantly associated with mortality from CRC. Subjects with lower BMI had greater mortality risk than those with higher BMI. The results of studies on the role of BMI on mortality from CRC have been inconsistent. Murphy et al.,
(2000) showed that obesity increases risk of dying from colon cancer, especially in men. But another study, which was published in 2009 by Hines et al., (2009) showed that in patients with colon cancer, underweight increases mortality while weight gain and obesity decreases mortality which is consistent with the current research results.

Differences in results of these studies may be due to differences in the number of clinical and patho- 
Cox vs log-logistic modeling in CRC patients Hashemian et al.,

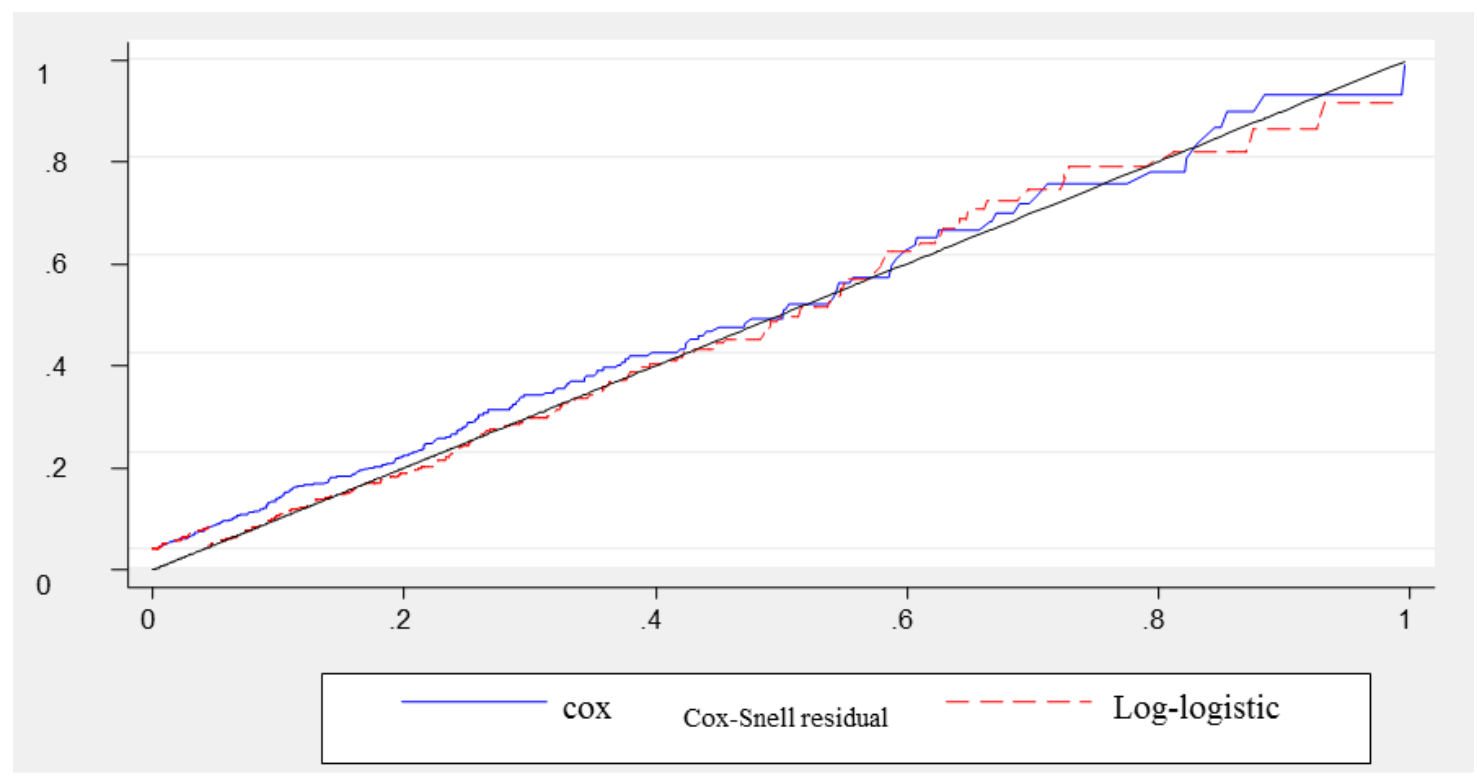

Figure 1: Cox Snell's residual for survival of patients with colorectal cancer in Cox and Loglogistic models

logical factors associated with statistical analysis of survival and type of selected population. Also, different levels of defined BMI and grouping patients to various groups of underweight, normal, overweight and obese can result in different findings. The time of BMI measurement can also affect the results; for example, measuring BMI of a person who is overweight can cause error in evaluation of the effect of BMI on survival after a surgery that reduces the person's BMI.

Ghadimi et al. (2010) compared Cox model and parametric models, without frailty, and proved that the parametric Log-logistic model performs better than Cox model as well as other parametric models in both univariate and multivariate analysis. Frailty parameter was also considered in this study, and based on the obtained results; poor tumor grade, tumor size $>35$ and $\mathrm{BMI}$ were significant in both cox in log -logistic model. Saki Malehi et al. (2012), findings showed that, considering Weibull model with the effects of frailty on analyzing the survival of CRC patients, inclusion of heterogeneity among individuals improves the model. Based on Akaike's criterion, Cox model performed better than Log-logistic model. Since the method of obtaining parameters in Cox model is different from parametric models use of Cox-Snell residual graph for evaluation of fitted models indicated that fitting processes of both models were the same.

\section{CONCLUSION}

Although the employed regression coefficients of Log-logistic and Cox models were the same, despite the desire of many researchers to use Cox model in survival analysis studies, parametric models can predict probability of the target event for long term and provide a clear picture of survival time and hazard function. Therefore, for this field of study, different parametric models of survival analysis are suggested to be used as the best choice and most efficient model. In addition, by having the survival time and its influencing factors in patients with CRC, better service can be provided and special measures can be taken in order to control and reduce mortality and increase survival of these patients.

\section{ACKNOWLEDGMENT}

This article is a part of research project approved by Student Research Committee, Kermanshah University of Medical Sciences (95046). The author of 


\section{Cox vs log-logistic modeling in CRC patients}

Hashemian et al.,

this article sincerely thanked the vice chancellor of Kermanshah medical science university for accepting the expanse of this project.

\section{COMPETING INTERESTS}

The authors declare that they have no competing interests.

\section{REFERENCES}

Ahmad Reza Baghestani, Mahmood Reza Gohari, Arezoo Orooji, Mohamad Amin Pourhoseingholi and Zali M.R. (2015) Evaluation of parametric models by the prediction error in colorectal cancer survival analysis. 8(3), 183 $-187$.

Ahmadi A., Hashemi Nazari S. and Mobasheri M. (2014) Survival time and relative risk of death in patients with colorectal cancer in an Iranian population: a cohort study. $J \mathrm{Ma}$ zandaran Univ Med Sci 24(111), 2-8.

Angell-Andersen E., Tretli S., Coleman M., Langmark F. and Grotmol T. (2004) Colorectal cancer survival trends in Norway 1958 -1997. European Journal of Cancer 40(5), 734742.

Berti R.E., Secco G., Lapertosa G., Di Somma C., Santi F. and Percivale P. (1983) Colorectal cancer: relationship of histologic grading to disease prognosis. Tumori 69(6), 581-584.

Chung C., Zaino R.J. and Stryker J.A. (1982) Colorectal carcinoma: evaluation of histologic grade and factors influencing prognosis. Journal of surgical oncology 21(3), 143-148.

Cox D. (1972) Regression models and life-tables. J Royal Stat Soci Serie B187-220.

Cusack J.C., Giacco G.G., Cleary K., Davidson B.S., Izzo F., Skibber J., Yen J. and Curley S.A. (1996) Survival factors in 186 patients younger than 40 years old with colorectal adenocarcinoma. Journal of the American College of Surgeons 183(2), 105-112.

Efron B. (1977) The efficiency of Cox's likelihood function for censored data. Journal of the American statistical Association 72(359), $557-$ 565.

Ganji A., Safavi M., Nouraie M., Nasseri-Moghadam S., Merat S. and Vahedi H. (2006) Digestive and Liver Diseases Statistics in Several Referral Centers in Tehran,2000-2004. 11(1), 33-38.

Ghadimi M., Mahmoodi M., Mohammad K., Zeraati H., Hosseini M. and Sheikh Fathollahi M. Comparison of Survival analysis of Gastrointestinal Cancer patients using parametric and Cox models. sjsph. 2010; 8 (2) $: 1-14$

Goh H., Goh C., Rauff A. and Foong W. (1987) Clinico-pathological prognostic factors of large bowel cancer in Singapore: a multivariate analysis. Annals of the Academy of Medicine, Singapore 16(3), 437-440.

Hines R.B., Shanmugam C., Waterbor J.W., McGwin G., Funkhouser E., Coffey C.S., Posey J. and Manne U. (2009) Effect of comorbidity and body mass index on the survival of African-American and Caucasian patients with colon cancer. Cancer 115 (24), 5798-5806.

Kalbfleisch J.D. and Prentice R.L. (1980) The Statistical Analysis of Failure Time Data. New York: Wiley 100-150.

Klein J. and Moeschberger M. Survival analysis techniques for censored and truncated data.2th ed.New York: Springer-V erlag,2003.393-405.

Kleinbaum D.G. and Klein M. (2005) Survival Analysis A Self-Learning Text. New York:Springer-verlag, Inc.

Lawless J.F. (1998) Parametric models in survival analysis. Encyclopedia of Biostatistics, New York: Wiley3254-3264.

Li M., Li J., Zhao A. and Gu J. (2008) Colorectal cancer or colon and rectal cancer? Oncology 73(1-2), 52-57.

Liang H., Wang X.-N., Wang B.-G., Pan Y., Liu N., Wang D.-C. and Hao X.-S. (2006) Prognostic factors of young patients with colon cancer after surgery. World journal of gastroenterology 12(9), 1458.

Melissa M., Ahmedin J. and Robert A. (2009) World wide variations in colorectal cancer. cancer journal for clinicians 59(6), 366-378.

Murphy T.K., Calle E.E., Rodriguez C., Kahn H.S. and Thun M.J. (2000) Body mass index and colon cancer mortality in a large prospec- 
tive study. American journal of epidemiology 152 (9), 847-854.

Oakes D. (1977) The asymptotic information in censored survival data. Biometrika 64(3), 441448.

Ogata Y., Torigoe S., Matono K., Sasatomi T., Ishibashi N., Shida S., Ohkita A., Mizobe T., Ikeda S. and Ogou S. (2005) Prognostic factors after potentially curative resection in stage II or III colon cancer. The Kurume medical journal 52(3), 67-71.

Park Y.J., Park K.J., Park J.-G., Lee K.U., Choe K.J. and Kim J.-P. (1999) Prognostic factors in 2230 Korean colorectal cancer patients: analysis of consecutively operated cases. World journal of surgery 23(7), 721-726.

Parkin D.M. (2001) Global cancer statistics in the year 2000. The lancet oncology 2(9), 533-543.

Phillips R., Hittinger R., Blesovsky L., Fry J. and Fielding L. (1984) Large bowel cancer: surgical pathology and its relationship to survival. British Journal of Surgery 71(8), 604-610.

Pourhoseingholi MA, Hajizadeh E, Moghimi Dehkordi B, Safaee A, Abadi A and MR Z. (2007) Comparing Cox Regression and Parametric Models for Survival of Patients with
Cox vs log-logistic modeling in CRC patients Hashemian et al.,

Gastric Carcinoma. Asian Pac J Cancer Prev 8(3), 412-416.

Sadjadi A., Malekzadeh R., Derakhshan M.H., Sepehr A., Nouraie M., Sotoudeh M., Yazdanbod A., Shokoohi B., Mashayekhi A. and Arshi S. (2003) Cancer occurrence in Ardabil: Results of a population-based Cancer Registry from Iran. International journal of cancer 107(1), 113-118.

Saki Malehi A., Hajizadeh E. and Ahmadi K. Weibull Frailty Model in Survival Analysis: An Application to Colorectal Cancer Patients. J. of Stat. Sci.. 2012; 6 (1) :69-82.

Stewart B.W. and Kleihues P. (2003) World cancer report: Lyon:International Agency for Research on Cancer

Takahashi K., Mori T. and Yasuno M. (2000) Histologic grade of metastatic lymph node and prognosis of rectal cancer. Diseases of the colon \& rectum 43(10), S40-S46.

Xu F., Di M., Dong J., Wang F., Jin Y., Zhu Y. and Lai M. (2006) [Influence of clinical and pathomorphological parameters on prognosis in colon carcinoma and rectal carcinoma]. Zhejiang da xue xue bao. Yi xue ban= Journal of Zhejiang University. Medical sciences 35(3), 303-310.
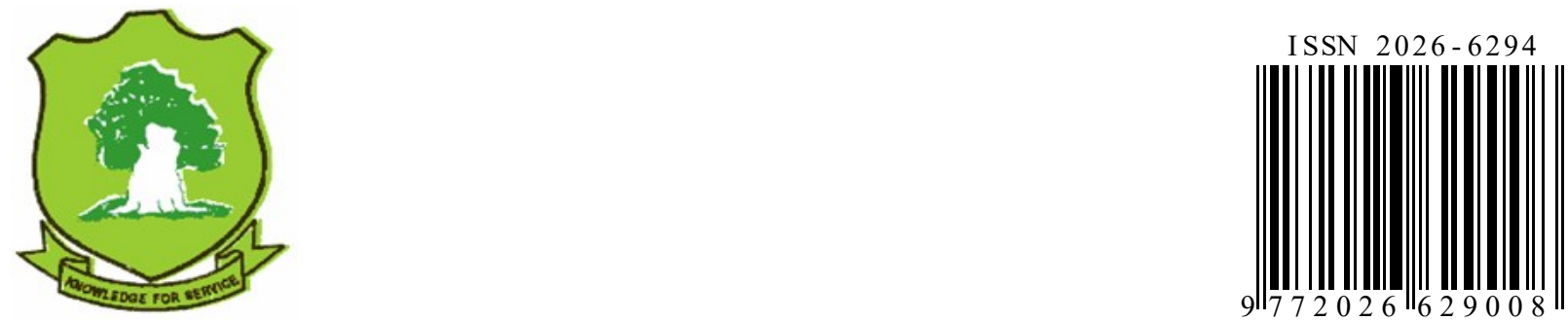